\title{
Современные данные
}

\section{о функциональных нарушениях желудочно-кишечного тракта у детей}

\author{
Contacts: \\ Gribakin Sergey Germanovich, Doctor of Medical Sciences, Professor, Scientific Consultant for FrieslandCampina \\ Address: 42 Varshavskoe shosse, Build. 3, Moscow 115320 , Tel.: (495) 775-25-08, e-mail: gribakin@anika-ru.ru
} Article received: 18.09.2013, Accepted for publication: 28.10 .2013

Функциональные нарушения пищеварения часто встречаются у детей первого года жизни. Врачи-педиатры нередко рекомендуют сменить одну детскую молочную смесь на другую, что обычно не приводит к положительным результатам, а только усложняет ведение таких детей. В статье приводятся современные взгляды на причины, патофизиологические механизмы и принципы диетотерапии синдрома срыгиваний, функциональных запоров, кишечных колик и других функциональных нарушений желудочно-кишечного тракта у детей раннего возраста. Особенностью данной группы патологических состояний является то, что они реже встречаются в виде моносимптомов и значительно чаще - в различных сочетаниях. При функциональных нарушениях желудочно-кишечного тракта при обследовании не удается обнаружить ни морфологических изменений со стороны органов пищеварительной системы, ни нарушений ферментовыделительной функции. Вместе с тем минимальные пищеварительные дисфункции негативно отражаются на качестве жизни семьи, на темпах развития и нутритивном статусе ребенка. Диетологические мероприятия относятся к числу наиболее эффективных методов коррекции этих состояний.

Ключевые слова: дети раннего возраста, срыгивания, функциональные запоры, кишечные колики, белки коровьего молока.

(Вопросы современной педиатрии. 2013; 12 (5): 60-65)

У детей первого года жизни нередко возникают функциональные нарушения пищеварения (срыгивания, запоры, кишечные колики, метеоризм), которые в ряде случаев становятся причиной обращения родителей к врачу-педиатру [1, 2]. Это нередко приводит к замене одних детских молочных смесей на другие, поскольку среди родителей (и отчасти среди врачей) бытует мнение, что подобная симптоматика означает «непереносимость детской молочной смеси". Однако показатели роста и развития детей в большинстве случаев остаются в пределах возрастной нормы.

\section{СРЫГИВАНИЯ (РЕГУРГИТАЦИЯ)}

Ежедневно возникающие срыгивания достигают частоты 86,9\% у детей двухмесячного возраста, а к 1 году частота их снижается до 7,6\% [3]. Наличие срыгиваний зависит от объема пищи: чем больше объем кормления, тем более продолжительна эвакуация пищи из желудка и выше внутрижелудочное давление, вследствие чего чаще возникает спонтанная реакция нижнего пищеводного сфинктера, которая способствует появлению гастроэзофагального рефлюкса (ГЭР).

S.G. Gribakin, T.I. Garankina, A.A. Davydovskaya

Limited Liability Company «Anika RU», Moscow, Russian Federation

\section{Current Data on Gastro-Intestinal Dysfunctions in Children}

Digestive dysfunctions are common in infants of the 1st year of life. Pediatricians often recommend shifting one milk formula to another, but usually it has no positive results, only complicating the managing of such patients. The article demonstrates the modern views on etiology, pathophysiological mechanisms and principles of dietary therapy of regurgitations, functional constipations, intestinal colic and other gastro-intestinal dysfunctions in infants. One of the special characteristics of these disorders is the fact that they rarely occur as isolated symptoms and much more often - in different combinations with each other. On clinical examination of children with functional disorders neither morphological changes in gastro-intestinal tract, nor disturbances in enzyme-secretory function are found. At the same time minimal digestive dysfunctions have negative effect on life quality of the family, development rate and nutritive status of the child. One of the most effective methods of correction of such conditions is dietary measures.

Key words: infants, regurgitations, functional constipations, intestinal colic, cow milk proteins.

(Voprosy sovremennoi pediatrii - Current Pediatrics. 2013; 12 (5): 60-65) 
Регургитацией называют заброс желудочного содержимого в глотку или ротовую полость или выброс из ротовой полости [4]. Рвоту определяют как рефлекс с участием центральной нервной системы с вовлечением автономных и скелетных мышц. ГЭР сопровождается ретроградным движением желудочного содержимого. Его расцени вают как физиологический процесс, который имеет место несколько раз в день у каждого здорового индивидуума. Согласно критериям рН-метрии, большинство эпизодов ГЭР по времени короче 3 мин происходит в постпрандиальный период (после приема пищи) и сопровождается неярко выраженными симптомами или протекает бессимптомно [5]. Согласно Римским критериям III пересмотра, диагноз регургитации (синдрома срыгиваний) у практически здоровых детей в возрасте от 3 нед до 12 мес должен включать регургитацию не менее 2 раз/сут на протяжении не менее 3 нед при отсутствии тошноты, гематемезиса, аспирации, апноэ, задержки роста, трудностей при глотании и неправильного положения (позы). Более 50\% всех детей соответствует этим критериям.

Подавляющее большинство детей с регургитацией являются практически здоровыми. Однако ребенок с повторными срыгиваниями нуждается в полном физикальном обследовании. Важным критерием является оценка антропометрических показателей, чтобы убедиться, правильно ли развивается ребенок [6]. При наличии рвоты или задержке темпов прибавки в весе нельзя говорить о физиологической регургитации.

Важным элементом профилактики синдрома срыгиваний является обучение родителей: они должны знать, что перекорм предрасполагает к возникновению срыгиваний даже при грудном вскармливании, а использование смесей с загустителем (AR-смесей) способствует снижению объема и частоты срыгиваний. Положение анти-Тренделенбурга (лежа на животе) не рекомендовано ввиду повышения риска синдрома внезапной детской смерти [7].

Исследования, посвященные использованию антисекреторных препаратов или прокинетиков, не показали их эффективности при физиологических срыгиваниях [8]. Среди детей с непереносимостью белков коровьего молока (БКМ) срыгивания и рвота клинически не отличимы от таковых с физиологическим ГЭР. Однако уменьшить частоту срыгиваний у них удается за счет элиминации БКМ из диеты (сроком не менее чем на 2 нед). Обратный перевод на обычную диету (содержащую БКМ) приводит к возобновлению симптомов. Следует напомнить, что продолжительность доказательных исследований, посвященных использованию высоких гидролизатов белка (таких, как Фрисопеп АС и другие) или смесей на основе аминокислот при синдроме срыгивания и рвоты не должна составлять меньше 4 нед.

Большинство эпизодов регургитации у здоровых детей короче 3 мин по времени происходит после приема пищи и может протекать бессимптомно или с минимальной симптоматикой [9]. Напротив, гастроэзофагальная рефлюксная болезнь (ГЭРБ) протекает с рефлюксом желудочного содержимого и сопровождается неприятными симптомами или осложнениями. В этом случае необходимо установить причины болезни. В лечении ГЭРБ следует использовать изменение образа жизни (применительно к детям - режима дня и методики кормления). В ряде случаев прибегают к медикаментозной терапии, в редких случаях - к хирургическому вмешательству.

Диетологические подходы при ГЭР включают использование АР-смесей, которые за счет загустителя повышают вязкость содержимого желудка, препятствуют срыгиванию, улучшают сон и урежают частоту эпизодов плача и беспокойства ребенка, а также восстанавливают темпы прибавки массы тела [10]. АР-смеси, широко используемые во всем мире, содержат в качестве загустителя рисовый, кукурузный или картофельный крахмал, гуаровую камедь или клейковину рожкового дерева.

Проводились исследования по влиянию загустителей в составе смеси на абсорбцию витаминов и минеральных веществ in vivo, причем отрицательного влияния зарегистрировано не было [11]. Дети с отставанием в физическом развитии и потерей веса на фоне синдрома срыгиваний должны наблюдаться у педиатра.

Наличие синдрома срыгиваний на фоне тяжелых проявлений атопического дерматита должно наводить на мысль о наличии гастроинтестинальных проявлений пищевой аллергии (непереносимость БКМ). В этих случаях диетотерапию следует начинать с высокогидролизованных смесей (Фрисопеп, Фрисопеп АС и др.) [12].

Также существуют рекомендации о приостановлении использования продуктов прикорма во время назначения диагностической элиминационной диеты. Интересно отметить, что назначение безмолочной диеты матерям, кормящим детей с непереносимостью БКМ грудью, не всегда дает желаемые результаты. К этому можно добавить, что наличие синдрома срыгиваний и ГЭР почти никогда не служат причиной отказа от грудного вскармливания.

\section{КИШЕЧНЫЕ КОЛИКИ}

Впервые описание кишечных колик было сделано Wessel и соавт. в 1954 г. [13]. Их определили как «приступы плача, продолжающиеся 3 и более часов в день, не менее 3 дней в нед и на протяжении не менее 3 нед". C некоторыми изменениями это определение отражено в III Римских критериях 2006 г., где указано, что детские кишечные колики - это эпизоды беспокойства, крика и плача, которые как начинаются, так и заканчиваются без видимых причин и продолжаются не менее 3 ч в день, не менее 3 дней в нед на протяжении не менее 1 нед. Колики встречаются примерно с одинаковой частотой у детей на естественном и на искусственном вскармливании, без различий по половому признаку [14]. Этиология этого состояния до сих пор неизвестна, хотя популярны различные гипотезы, такие как нарушение функции желудочно-кишечного тракта вследствие наличия пищевой аллергии (непереносимость БКМ), транзиторной лактазной недостаточности или ГЭР $[15,16]$.

Не существует единых критериев для назначения схемы лечения. Следует оценить методику кормления и характер питания. При грудном вскармливании матери рекомендуют перейти на безмолочную диету. Элиминационную диету следует соблюдать не менее 2 нед, а при наличии положительных результатов продолжать ее. Детям, находящимся на искусственном вскармливании, показана элиминационная диета с переводом на смеси-гидролизаты с высокой степенью гидролиза. Клинический опыт свидетельствует, что продуктами 
выбора могут быть также смеси на основе частичного гидролиза (например, Фрисолак ГА 1 и 2 и др.). Они рекомендованы, если колики не сочетаются с клиническими проявлениями атопического дерматита, и к тому же имеют преимущества перед глубокими гидролизатами в отношении цены. Эффективность указанных смесей при детских коликах подтверждена в рандомизированных контролируемых исследованиях $[17,18]$. Более того, в ряде случаев эти смеси содержат пребиотики или относятся к низколактозным смесям, что также способствует снижению частоты эпизодов колик в неделю. Однако ряд специалистов оспаривает роль лактозы, поскольку соевые смеси (тоже безлактозные) не оказывают аналогичного действия.

Изучение эффективности препаратов с симетиконом не продемонстрировало преимуществ при сравнению с плацебо [19].

Определенные надежды возлагают на использование пробиотиков, хотя этот вопрос нуждается в дальнейших исследованиях [20]. Ингибиторы протонной помпы при кишечных коликах оказались неэффективны [21].

Мультифакториальная природа кишечных колик не позволяет склониться к какому-то единственному решению этой проблемы. Из всех предлагаемых подходов доказанным эффектом обладают только смесигидролизаты с высокой степенью гидролиза и, в несколько меньшей степени, частичные гидролизаты.

\section{METEОРИЗМ}

Повышенное газообразование причиняет ребенку болевые ощущения, поэтому в реальной жизни жалобы родителей заключаются в беспокойстве и плаче ребенка, тогда как причина этого явления может оставаться неустановленной. Именно поэтому важен осмотр ребенка и сбор анамнеза.

Причины плача ребенка многообразны, начиная от чувства голода и дискомфорта и кончая жизнеугрожающими состояниями. Вполне здоровый ребенок кричит от 20 мин до 3,5 ч/сут [22]. В зависимости от психической устойчивости родителей это действует на них по-разному, вплоть до стресса, фрустрации и лишения сна, что может стать причиной обращения к врачу [23]. Очень часто наличие метеоризма трудно отличить от вышеописанных кишечных колик, поскольку внешние проявления во многом сходны.

Симптоматика повышенного газообразования и метеоризма в большинстве случаев не связана с какимито медицинскими проблемами. Наличие определенного количества газа в просвете пищеварительного тракта вполне нормальное явление. Симптомы возникают лишь при избыточном газообразовании, что вызывает растяжение петель кишечника и сопровождается болевыми ощущениями. Это состояние может усиливаться за счет аэрофагии при кормлении. Само по себе повышенное газообразование не представляет опасности, но следует обратить внимание на другие возможные симптомы, которые служат сигналом тревоги: частые срыгивания, кровь в стуле, диарея, потеря веса, астма или атопия у членов семьи или прием матерью лекарственных препаратов. Иногда при обследовании у таких детей обнаруживается гиполактазия [24]. Нельзя оставлять без внимания часто плачущих детей, поскольку при более подробном их обследовании в 66,3\% случаев удается установить непосредственную причину [25].

\section{ФУНКЦИОНАЛЬНЫЕ ЗАПОРЫ}

Для детей, которым еще не исполнилось 4 мес, определяющую роль в характере стула играет вид вскармливания. Здоровые дети, находящиеся на грудном вскармливании, имеют частоту стула до 12 раз/сут. Частота запоров у таких детей составляет всего 1,1\%, тогда как у детей на искусственном вскармливании - 9,2\% [26]. Даже несмотря на использование про- и пребиотиков, частота запоров у маленьких детей составляет порядка $10 \%$. Нередко запоры возникают при переходе от естественного к искусственному вскармливанию [27].

Если у новорожденного в первые 24-48 ч нет самостоятельного стула, и не отходит меконий, есть основания заподозрить болезнь Гиршпрунга. Также немаловажно выяснить, что имеют в виду сами родители, когда обращаются с жалобами на запоры у ребенка: длительность времени между дефекациями, частоту стула или его консистенцию, болезненную дефекацию или наличие свежей крови в стуле. Применительно к детям многие педиатры используют определение запора, данное Biggs и Dery [28]: “Затрудненная или редкая дефекация на протяжении 2 последних недель". Диагноз "Функциональный запор" ставят на основании анамнестических данных и физикального исследования. Если нет подозрения на органические причины, дополнительного обследования не требуется. Чем меньше возраст ребенка, тем более высок риск анатомических или органических причин, хотя частота функциональных запоров остается высокой в любом возрасте.

При обследовании важно уделить внимание аноректальной зоне, оценить перианальную чувствительность, расположение и тонус анального отверстия, размер прямой кишки, объем и консистенцию стула, его расположение в прямой кишке. При наличии боли, вздутия живота, перемежающейся диареи может потребоваться дополнительное обследование. Одной из возможных причин запоров у детей считается непереносимость БКМ, однако патогенетические звенья, равно как и частота этого явления, остаются малоизученными [29].

При планировании лечения функциональных запоров у детей грудного возраста необходимо провести разъяснительную работу с родителями. Важно объяснить, что это одна из наиболее частых проблем, не представляющих большой опасности, склонная к спонтанному разрешению. Важно исключить наличие органических причин. Если ребенок находится на искусственном вскармливании, нет оснований срочно менять смесь. В ряде стран существуют рекомендации по использованию фруктовых соков, обладающих легким послабляющим эффектом (сливовый, персиковый, яблочный). Особое место в лечении функциональных запоров занимают антирефлюксные смеси с клейковиной рожкового дерева [30, 31].

\section{ФУНКЦИОНАЛЬНЫЕ НАРУШЕНИЯ ЖЕЛУДОЧНО-КИШЕЧНОГО ТРАКТА \\ И АЛЛЕРГИЯ К БЕЛКАМ КОРОВЬЕГО МОЛОКА}

Несмотря на отсутствие точной статистики, непереносимость БКМ является одной из наиболее частых 
причин пищевой аллергии у детей во всем мире [32]. У детей с симптомами со стороны желудочно-кишечного тракта, такими как рвота и диарея, весьма часто имеет место непереносимость БКМ. Постановка правильного диагноза в этих случаях может вызвать затруднения, поскольку необоснованная элиминационная безмолочная диета может стать причиной задержки роста и гипотрофии [33].

Согласно определению, предложенному экспертами Всемирной аллергологической организации, непереносимость БКМ представляет собой реакцию гиперчувствительности к БКМ, обусловленную специфическими иммунологическими механизмами. Непереносимость БКМ - гетерогенная группа нарушений, которая включает:

- IgЕ-опосредованные формы;

- смешанную IgE/неlgE-опосредованную форму;

- нelgЕ-опосредованную форму.

IgE-опосредованная форма вызвана гиперчувствительностью к БКМ немедленного типа, которая часто связана с атопическими заболеваниями, такими как атопическая экзема, астма или аллергический ринит. Симптоматика со стороны желудочно-кишечного тракта в виде рвоты, диареи или колик обычно сопутствует системным проявлениям со стороны кожи (крапивница, сосудистый отек) или респираторного тракта (кашель, бронхоспазм, ринит), сопровождаясь бледностью и гипотензией, вскоре (в течение 1 ч) после воздействия аллергена. $\mathrm{K}$ наиболее серьезным проявлением IgEопосредованной непереносимости БКМ относятся анафилактические реакции. В ряде случаев бывает непросто провести дифференциальную диагностику между рефлюксом и непереносимостью БКМ.

Как смешанная IgE/нelgE-опосредованная, так и нelgE-опосредованная форма аллергии представляют собой неоднородную группу заболеваний, и участвующие в них иммунологические механизмы не всегда ясны.

Основным принципом лечения пациентов с пищевой аллергией является элиминация причинно значимого фактора из диеты пациента. Для растущего организма ребенка элиминационная диета должна строиться индивидуально, чтобы обеспечить безопасный и полноценный рацион до формирования толерантности к БКМ. В ряде регионов мира прослеживается тенденция к гипердиагностике непереносимости БКМ и недостаточному контролю адекватности назначаемых элиминационных диет. Такая практика зачастую приводит к гипотрофии и развитию дефицитных состояний [34]. Однако в других регионах можно столкнуться с недооценкой и гиподиагностикой, поэтому важно стремиться к более точной диагностике.

Детям с симптомами, указывающими на IgE-опосредованную реакцию, показано назначение элиминационной диеты. Для диагностики могут быть использованы кожные прик-тесты и определение специфических IgE. Провокационно-элиминационная проба является "золотым стандартом" в постановке диагноза непереносимости БКМ [35].

Дети с непереносимостью БКМ должны находиться на катамнестическом наблюдении. У большинства из них с возрастом формируется толерантность к БКМ: в четырехлетнем возрасте - в 19\%, в восьмилетнем - в $42 \%$, в шестнадцатилетнем - в 79\% случаев [36]. У детей с IgEотрицательной формой аллергии толерантность формируется раньше.

Большинство педиатров полагают, что смеси на основе БКМ должны быть заменены на гипоаллергенные. В большинстве международных и национальных рекомендаций соевые смеси исключены из продуктов первого ряда при непереносимости БКМ [37]. В этих рекомендациях проводится детализация в зависимости от типа реакции, возраста пациента, доступности продуктов и стоимости лечения.

Рисовые гидролизаты, популярность которых во многих странах быстро растет, скоро будут включены в подобные рекомендации, поскольку они лишены аллергенов коровьего молока, содержат высокогидролизованный рисовый белок (и имеют низкую резидуальную аллергенность), а по стоимости предпочтительнее высокогидролизованных смесей на основе БКМ. Однако клинический опыт их применения еще недостаточен для широкого использования.

В современных рекомендациях экспертов Всемирной аллергологической организации предложено у детей c IgEопосредованной непереносимостью БКМ при низком риске анафилактической реакции использовать смеси на основе глубокого гидролизата. Именно этим продуктам отдают предпочтение по сравнению с аминокислотными смесями ввиду высокой стоимости последних. Однако для детей с высоким риском анафилактических реакций выбор может быть сделан в пользу аминокислотных смесей. Вместе с тем эти же рекомендации содержат упоминание о том, что хотя высокогидролизованные смеси и имеют преимущества перед смесями на основе изолята соевого белка, вопрос выбора нельзя считать окончательно решенным. Опыт использования соевых смесей насчитывает без малого 100 лет, и отношение к ним не везде одинаково. Например, они остаются популярными в США, но почти забыты во Франции [37].

Американская академия педиатрии рекомендует начинать диетотерапию детей c IgE-опосредованной непереносимостью БКМ с высокогидролизованных, а не соевых смесей [38]. Эксперты указывают, что сенсибилизацию к сое имеют от 10 до 14\% детей с непереносимостью БКМ. Однако существуют данные, что реальный процент аллергии к соевому белку намного ниже. При обследовании 13019 детей c IgE-опосредованной непереносимостью БКМ только 66 (0,5\%) имели аллергию к соевомy белку. Однако среди детей с нelgE-опосредованной формой аллергия на сою встречалась намного чаще, и соевых смесей в этом случае следовало избегать [39]. Тем не менее соевые смеси не могут быть продуктами выбора, хотя могут оставаться продуктами резерва при непереносимости БКМ.

Таким образом, высокая частота функциональных расстройств желудочно-кишечного тракта у детей раннего возраста еще не является поводом для того, чтобы часто и необдуманно заменять одни детские молочные смеси на другие. Рекомендации по питанию детей в подобных ситуациях должны быть клинически обоснованными, с привлечением имеющегося отечественного и зарубежного опыта. 


\section{REFERENCES}

1. Funktsional'nye Narusheniya Zheludochno-Kishechnogo Trakta u Detey Grudnogo Vozrasta i Ikh Dietologicheskaya Korrektsiya [Functional Disorders of the Gastrointestinal Tract in Infants and their Nutritional Correction]. In the book: Lechebnoe Pitanie Detey Pervogo Goda Zhizni [Therapeutic Nutrition of Infants]. Under the general editorship of A.A. Baranov, V.A. Tutelyan. Klinicheskie Rekomendatsii dlya Pediatrov [Clinical Guidelines for Pediatricians]. Moscow, Soyuz Pediatrov Rossii Publ., 2010. P. 51-64.

2. Funktsional'nye Narusheniya Zheludochno-Kishechnogo Trakta u Detey Grudnogo Vozrasta i Ikh Dietologicheskaya Korrektsiya [Functional Disorders of the Gastrointestinal Tract in Infants and their Nutritional Correction]. In the book: Natsional'naya Programma Optimizatsii Vskarmlivaniya Detey Pervogo Goda Zhizni v Rossiyskoy Federatsii [National Program for Optimization of Infants Feeding in the Russian Federation]. Moscow, Soyuz Pediatrov Rossii Publ., 2010. P. 39-42.

3. Hyman H.E., Milla P.J., Benninga M. A., Davidson G. P., Fleisher D.F., Taminau J. Childhood functional gastrointestinal disorders: neonate/toddler. Gastroenterology. 2006; 130: 1519-1526.

4. Sherman P.M., Hassall E., Fagundes-Neto U., Cold B. D., Kato S., Kolezko S. A global evidence-based consensus on the definition of gastroesophageal reflux disease in the pediatric population. Am. J. Gastroenterol. 2009; 104: 1278-1295.

5. Vandenplas Y., Rudolph C. D., Di Lorenzo C., Hassall E., Liptak G. Pediatric gastroesophageal reflux clinical practice guidelines. Joint recommendations of the North America Society for pediatric gastroenterology, hepatology and nutrition (NASPGHAN) and European Society for pediatric gastroenterology, hepatology and nutrition (ESPGHAN). J. Pediatr. Gastroenterol. Nutr. 2009; 49: 498-547.

6. Sindrom Rvoty i Srygivaniya u Detey. Posobie dlya Vrachey [Vomiting and Regurgitation Syndrome in Children. Manual for Physicians]. Edited by I. N. Zakharova, N. A. Korovina, M. I. Pykova et al. Moscow, 2009. 140 p.

7. Moon R.Y. Task force on sudden infant death syndrome, SIDS and other sleep-related infant deaths: expansion of recommendations for a safe infant sleeping environment. Pediatrics. 2011; 128: 1030-1039.

8. Horvath A., Dziechciarz P., Szaewska H. The effect of thickenedfeed intervention on gastroesophageal reflux in infants: systematic review and meta-analysis of randomized controlled trials. Pediatrics. 2008; 122: 1268-1277.

9. Costalos C., Kapiki A., Apostolou M., Papathoma E. The effect of a prebiotic supplemented formula on growth and stool microbiology of term infants. Early Hum. Dev. 2008; 84: 45-49.

10. Borovik T. E., Skvortsova V. A., Yatsyk G. V. et al. Funktsional'nye Narusheniya Zheludochno-Kishechnogo Trakta u Detey Grudnogo Vozrasta: Rol' Dietoterapii [Functional Disorders of the Gastrointestinal Tract In Infants: The Role of Diet Therapy]. Lechashchiy vrach [Doctor in Charge]. 2011; 6: 66-69.

11. Aggett P.G., Agostoni C., Goulet O., Hernell O., Kolezko B., Lafeber $\mathrm{H}$. Antireflux or antiregurgitation milk products for infants and young children. A commentary by the ESPGHAN Committee on Nutrition. J. Pediatr. Gastroenterol. Nutr. 2002; 34: 496-498.

12. American Academy of Pediatrics, Committee on Nutrition. Hypoallergenic infant formulas. Pediatrics. 2000; 106: 346-349.

13. Wessel M.A., Cobb J.C., Jackson E.B., Harris G.S. Paroxysmal fussing in infancy, sometimes called "colic". Pediatrics. 1954; 14: 421-435.

14. Shergill-Bonner R. Infantil colic: practicalities of management, including dietary aspects. J. Fam. Health Care. 2010; 20: 206-209. 15. Cohen-Silver J., Ratnapalan S. Management of infantile colic: a review. Clin. Pediatr. 2009; 48: 14-17.
16. Critch J. Infantil colic: is there a role for dietary intervention? Pediatr. Child. Health. 2011; 16: 47-49.

17. Lucassen P. L., Assendelft W.J., Gubbels J.W., van Eijk J.T., Douwes A.C. Infantile colic: crying time reduction with a whey hydrolysate: A double-blind, randomized, placebo-controlled trial. Pediatrics. 2000; 106 (6): 1349-1354.

18. Savino F., Palumeri E., Castagno E., Cresi F., Dalmasso P., Cavallo F., Oggero R. Reduction of crying episodes owing to infantile colic: A randomized controlled study on the efficacy of a new infant formula. Eur. J. Clin. Nutr. 2006; 60 (11): 1304-1310.

19. Metcalf T.J., Irons T.G., Sher L.D., Young P.C. Simethicone in the treatment of infantile colic: a randomized, placebo-controlled multicenter study. Pediatrics. 1994; 94: 29-34.

20. Savino F., Cordisco I., Tarasco V. Lactobacillus reuteri DSM 17938 in infantile colic: a randomized, placebo controlled trial. Pediatrics. 2010; 126: 526-533.

21. Chen I.L., Gao W.Y., Johanson A.P., Niak A., Troiani J. Proton pump inhibitor use in infants: FDA reviewer experience. Gastroenterol. Nutr. 2012; 54: 8-14.

22. Baildam E. M. Duration and pattern of crying in the first year of life. Dev. Med. Child. Neurol. 1995; 37: 345-353.

23. St. James-Roberts I., Peachey E. Distinguishing infant prolonged crying from sleep-waking problems. Arch. Dis. Child. 2011; 96: 340-344.

24. Gormally S. Clinical clues to organic ethiologies in infants with colic. In: New evidence on unexplained early infant crying: its origins, nature and management. R. Barr, I. St. James-Roberts (eds.). Johnson\& Johnson Pediatric Institute. 2001. P. 133-149.

25. Freedman S. B., Al-Harthy N., Thull-Freedman J. The crying infant: diagnostic testing and frequency of serious underlying disease. Pediatrics. 2009; 123: 841-848.

26. Sorvacheva T. N., Pashkevich V.V., Kon'I.Ya. Dietoterapiya Zaporov u Detey Pervogo Goda Zhizni [Diet Therapy of Constipation in Infants]. In the book: Rukovodstvo po Detskomu Pitaniyu [Guidelines for Child Nutrition]. Edited by V.A. Tutelyan, I.Ya. Kon'. Moscow, MIA Publ., 2009. P. 519-526.

27. Tunc V.T., Camurdan A.D., Illah M.N., Sahin F., Beyazova U. Factors associated with defecation patterns in 0-24 month-old children. Eur. J. Pediatr. 2008; 167: 1357-1362.

28. Biggs W.S., Dery W. H. Evaluation and treatment of constipation in infants and children. Am. Fam. Phys. 2006; 73: 469-477.

29. Eigenmann P. A., Zamora S. A., Belli D. C. Cow's milk and chronic constipation in children. N. Engl. J. Med. 1999; 340: 891.

30. Anokhin V.A., Khasanova E.E., Urmancheeva Yu.R. et al. Otsenka Klinicheskoy Effektivnosti Smesi Frisovom v Pitanii Detey s Disbakteriozom Kishechnika Razlichnoy Stepeni i Minimal'nymi Pishchevaritel'nymi Disfunktsiyami [Evaluation of the Clinical Effectiveness of the Frisovom Mixture in Nutrition of Children with Varying Degrees of Intestinal Dysbiosis and Minimal Digestive Dysfunctions]. Voprosy sovremennoy pediatrii [Current Pediatrics]. 2005; 3: 75-79.

31. Yolkina T. N., Kondyurina E.G., Surovikina E.A., Gribanova O.A. Otsenka Effektivnosti Antireflyuksnoy Smesi s Prebiotikami dlya Korrektsii Funktsional'nykh Rasstroystv Pishchevareniya u Detey Pervykh Mesyatsev Zhizni [Evaluating the Effectiveness of Antireflux Mixtures with Prebiotics for the Correction of Digestive System Functional Disorders in Infants]. Voprosy detskoy dietologii [Problems of Pediatric Nutritiology]. 2011; 6: 53-57.

32. Sackesen C., Assaad A., Baena-Cagnali C., Ebisawa M., Fiocchi A., Heine R. G. Cow' s milk allergy as a global challenge. Curr. Opin. Allergy Clin. Immunol. 2011; 11: 243-248.

33. Fiocchi A., Schunemann H.J., Brozek J., Restani R. et al. Diagnosis and rationale for action against cow's milk allergy. A summary report. J. Allergy Clin. Immunol. 2010; 51: 599-607. 
34. Henriksen C., Eggesbo M., Halvorsen R., Botten G. Nutrient intake among two-years old children on cow's milk restricted diets. Pediat. Clin. North Am. 2009; 56: 1085-1103.

35. Boyce J. A., Assaad A., Burks A. W., Jones S. A. et al. Guidelines for the diagnosis and management of food allergy in United States. Report of NIAID-sponsored expert panel. J. Allergy Clin. Immunol. 2010; 126 (6): 1-58.

36. Skripak J.M., Matsui E. C., Mudd K. The natutal history of IgEmediated cow's milk protein allergy in infants. Arch. Dis. Child. 2007; 92: 902-908.
37. Vandenplas Y., De Greef E., Devreker T., Hauser B. Soy infant formulas: is it that bad? Acta. Paediatr. 2011; 100: 162-166.

38. Bhatia J., Greer F. American Academy of Pediatrics Committee on Nutrition. Use of soy protein-based formulas in infant feeding. Pediatrics. 2008; 121: 1062-1068.

39. Klemola T., Vanto T., Juntunen-Backman K. Allergy to soy formula and to extensively hydrolysed whey formula in infants with cow's milk allergy: a prospective randomized study with a follow-up to the age of 2 years. J. Pediatr. 2002; 140: $219-224$. 